\title{
Growth of single-crystalline strontium titanate fibers using LHPG technique
}

\author{
Jorge-Enrique Rueda-P1, Antonio Carlos Hernandes²
}

${ }^{1}$ Departamento de Física, Universidad de Pamplona, CP 543050, Pamplona, Colombia

${ }^{2}$ Instituto de Física de São Carlos, Universidade de São Paulo, CP 369, CEP 13566-970, SP, Brazil.

\begin{abstract}
Strontium titanate is an incipient ferroelectric material of the perovskite structure and high melting point $\left(2080^{\circ} \mathrm{C}\right)$. It is a material which has a remarkable chemical and thermal stability, and has an interesting potential for the development of applications, particularly in manufacturing laser diodes, sensors oxygen at elevated temperatures, UV sensors, and optical sensors, among other possibilities of development new optical devices. We present growth results $\mathrm{SrTiO}_{3}$ crystal fiber by the "Laser Heated Pedestal Growth" technique.
\end{abstract}

Keywords: Crystal Growth, Fibers, LHPG, Strontium Titanate.

\section{Crecimiento de fibras mono-cristalinas de titanate de estroncio utilizando la técnica LHPG}

\section{Resumen}

El titanate de estroncio es un material ferroeléctrico incipiente, de estructura perovskite $y$ alto punto de fusión $\left(2080^{\circ} \mathrm{C}\right)$. Es un material con notable estabilidad química y térmica, con un interesante potencial para el desarrollo de aplicaciones, particularmente en la construcción de diodos láser, sensores de oxígeno a elevadas temperaturas, sensores UV, sensores ópticos, entre otras posibilidades de desarrollos de nuevos dispositivos ópticos. En este trabajo, presentamos los resultados del crecimiento de fibras mono-cristal de SrTiO3, utilizando la técnica de fusión láser LHPG.

Palabras clave: Crecimiento de cristales, Fibras, LHPG, Titanato de estroncio.

\footnotetext{
*Para citar este artículo: Rueda-P,Jorge-E ; Hernandes, C.A. Crecimiento de fibras mono-cristalinas de titanate de estroncio utilizando la técnica LHPG . Revista Bistua.2015.13(2):24-28

+ Autor para el envió de correspondencia y la solicitud de las separatas: Rueda-P,Jorge-E., Departamento de Física, Universidad de Pamplona, e-mail: jorgeenriquerueda@gmail.com
} 
25

\section{Introduction}

Strontium titanate is considered foundational material of complex oxides electronics. Depending on conditions, this may have ionic conduction or electronic type (p) or $(n)^{1}$. Persistent photoconductivity was observed in strontium titanate single crystals when vacancies are produced in $\mathrm{it}^{2}$. This property of the strontium titanate will enable new application fields, being of particular interest the development of active optical memories. In this way, the "Laser-Heated Pedestal Growth (LHPG)" method allow growth to single-crystalline fibers of millimeter and sub-millimeter dimensions. LHPG technique compared with the conventional crystal growth methods has significant advantages, such as high pull rate $(\mathrm{mm} / \mathrm{min})$, not used crucible, allow crystals growth with high melting point $\left(\geq 1500^{\circ} \mathrm{C}\right)$ and melting zone has its reduced size $\left(<1 \mathrm{~mm}^{3}\right)^{3,4}$.

In this work, we present result of the single-crystal strontium titanate fiber growth. The fibers were obtained from pedestals constructed by the technique of solid state and cold extrusion. The results presented are the preliminary study to search for persistent photoconductivity in singlecrystalline strontium titanate fibers for optical applications.

\section{Method and materials}

Figure 1(a) shows a schematic of the LHPG system used. The growth system consists of an optical arrangement whose radiation source is a $\mathrm{CO}_{2}$ laser (Synrad model: Evolution $125 / 100 \mathrm{~W} / \lambda=10.6 \mu \mathrm{m})$.

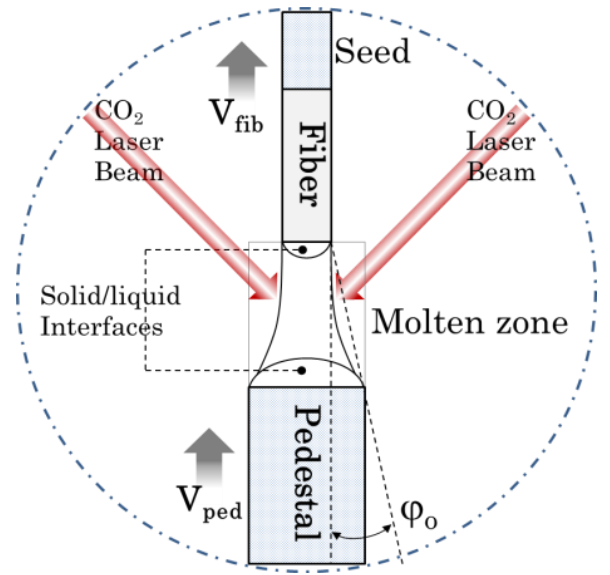

(a).

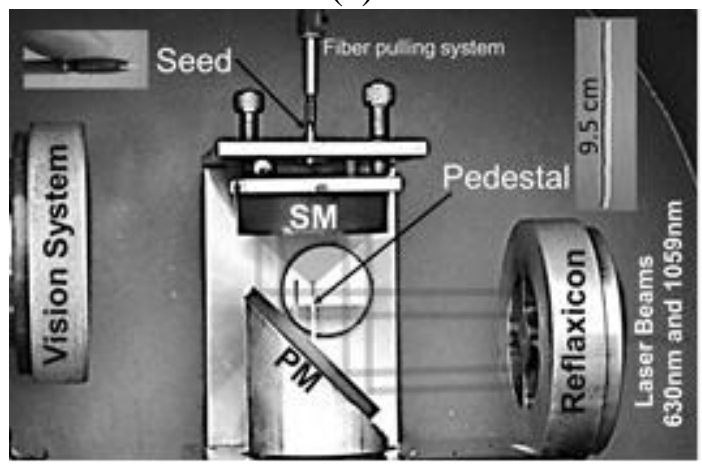

(b).

Figure 1. (a) Schematic drawing of the Laser Heated Pedestal Growth system. (b) Photography inside the growth chamber LHPG used in this work. SM: spherical mirror; PM: plane mirror.

The laser is focused on top of the pedestal to create the molten zone. To start the pulling of the singlecrystal fiber, the seed is inserted into the melted zone and removed in a way controlled to the surface of the liquid phase. This permits the crystallization of the compound in the contact between the solid/liquid interfaces. 
The growth process is guided by a computer, which controls the growth rate $\left(\mathrm{V}_{\mathrm{fib}}\right)$, and $\mathrm{CO}_{2}$ laser power, and the feed rate $\left(\mathrm{V}_{\text {ped }}\right)$ is manually controlled (in general, it is fixed). In this way, the diameter of de fiber is controlled. The growth process is summarized in the Figure 2. Sintering, synthesis and pulling fiber occur during this growth process.

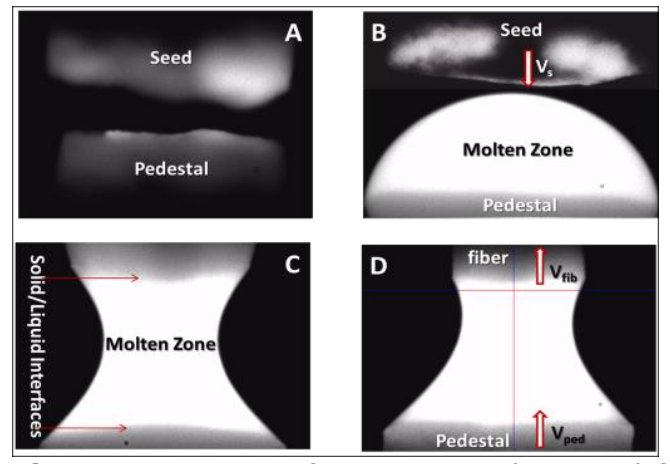

Figure 2. Images of growing single-crystal fiber by LHPG system (Fig.1). A, B, C and D are the steps of the fiber growth process. Step $A$ : mechanical alignment of the pedestal and seed. Step B: creation of a small molten zone on the top of the pedestal. Step C: Contact of the seed with the melted region pedestal. Step D: fiber growth.

The melted zone form is a very important growth parameter. The variation of the contact angle $\left(\varphi_{0}\right)$ is responsible by the fiber diameter fluctuation ${ }^{3}$. Minimum variations of this parameter commit the growth stability. Ideally, when the contact angle reaches this equilibrium value, the growth process is stable and should not have fluctuations. However, the real conditions of the growth system produce fluctuations in the form of the floating zone, thus modifying the contact angle.

The LHPG system operates through four basic steps: (1) Mechanical alignment of the seed and the pedestal (Fig.2A), both aligned on the optical axis of the laser beam; (2) Creation a molten zone small on the pedestal top. (Fig.2B), slowly increasing the laser power; (3) The seed is then introduced in the liquid phase and there is creation a molten zone (Fig.2C); (4) The motors are started and the pullingfiber process begins, with controlling manually or automatically the fiber diameter. (Fig.2D). The pedestals were prepared by solid state and cold extrusion methods. $\mathrm{SrCO}_{3}+\mathrm{TiO}_{2}$ stoichiometric mixture, under both precursor powder of high purity $(99.8 \%$ purity -Vetec-) was prepared. The pedestals have a circular cross section form (Approximate diameter: $1.65 \mathrm{~mm}$ ). This format is suitable for LHPG technique. In the growth process of the fiber, the following reaction takes place:

$\mathrm{SrCO}_{3}+\mathrm{TiO}_{2}+\Delta \mathrm{T} \uparrow \rightarrow \mathrm{SrTiO}_{3}+\frac{1}{2} \mathrm{O}_{2}+\mathrm{CO}$ 
Results and discussion

Images of the $\mathrm{SrTiO}_{3}$ fibers obtained are depicted en Figure 3. All growth was done in an air atmosphere.

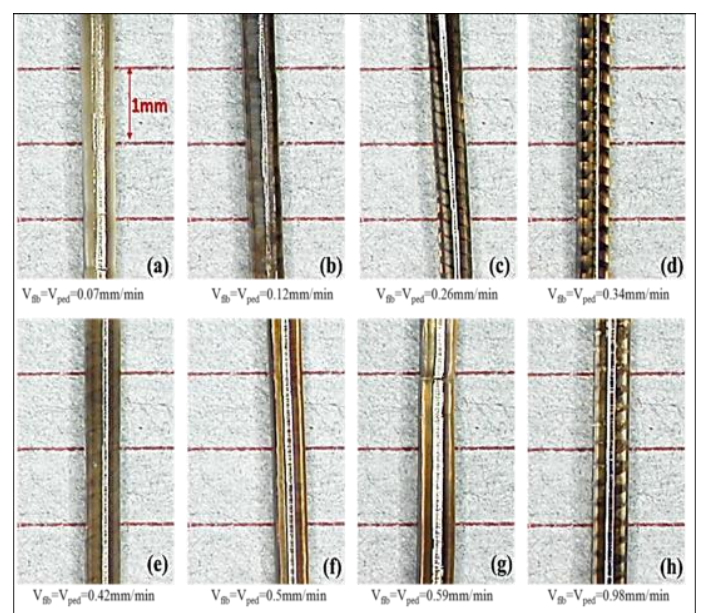

Figure 3. Images of the strontium titanate fibers, these were obtained with different rates of growth and feeding.

As it can be seen in Figure 3, all fibers have yellow and red color tones, this being an indicative of the generation of oxygen vacancies in the fiber [4]. In LHPG technique is presented high thermal gradient, where the cooling rate is $43^{\circ} \mathrm{C} / \mathrm{min}$, approximately. This high thermal gradient is responsible by the generation of oxygen vacancies in the fiber during its growth.

Figure 4 is the result of the phase obtained by X-ray diffraction, using the powder method. On the same Figure 4 are shown: the XRD patterns of the pedestal and fiber, and the XRD pattern reference ${ }^{5}$. All XRD pattern peaks of the fiber coincide with the XRD reference. We use the six peaks of the fiber XRD pattern to calculate the lattice parameter $(\bar{a}=3.9098 \AA)$. In the fiber XRD pattern only is observed the presence of the strontium titanate crystalline phase.

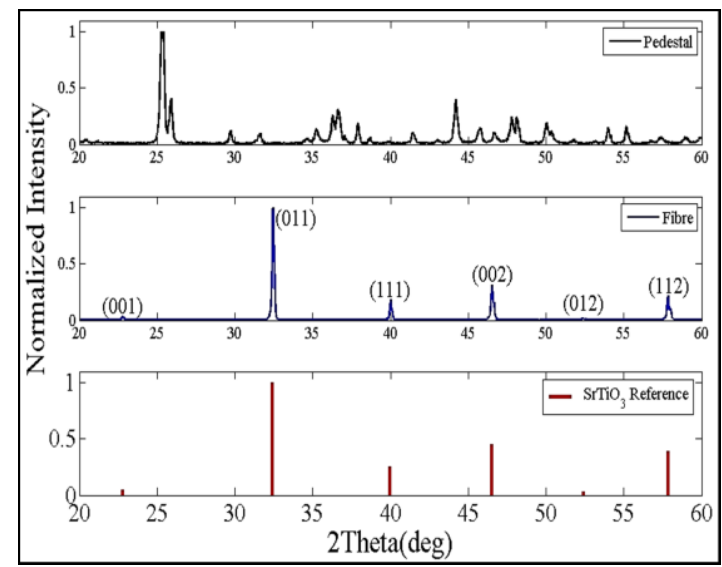

Figure 4. XRD pattern of: $\left(\mathrm{SrCO} 3+\mathrm{TiO}_{2}\right)$ pedestals, crystalline fiber powder, and reference pattern. Space-Group Pm-3m (221)-Cubic; $\bar{a}=3.9098 \AA$ average value determined from the XRD pattern of the fiber.

The results presented in this work are preliminary tests of the final objective. The idea is obtain fibers with persistent photoconductivity for optical applications. The research should lead us to determine the growth rates, necessary to obtain single-crystal fibers, high quality optical, and with persistent photoconductivity in the electromagnetic spectrum optical region. 


\section{References}

1. Steinsvik, S., Larring, Y., Norby, T., Hydrogen ion conduction in ironsubstituted strontium titanate, $\mathrm{SrTi} 1-\mathrm{x}$ Fex $03-x / 2 \quad(0<=x<=0.8)$, Solid State Ionics.2001. 143: 103-116.

2. Tarun, M.C., Selim, F.A., McCluskey, M.D., Persistent Photoconductivity in Strontium Titanate, Phys. Rev. Lett., PRL 111.2013: 187403-1 - 187403-5.

3. Andreeta, M.R.B., Hernandes, A.C., Laser-Heated Pedestal Growth of Oxide Fibers, Cap. Part.B de Handbook of Crystal Growth, 393-432. Springer, 2010.

4. Ardila, D. R., Andreeta, M.R.B., Cuffini, S.L., Hernandes, A.C., Andreeta, J.P., Singlecrystal $\mathrm{SrTiO}_{3}$ fiber grown by laser heated pedestal growth method: Influence of ceramic feed rod preparation in fiber quality, Mater. Res.1998. 1, 11.

5. Abramov, Yu. A.; Tsirelson, V. G. ; Zavodnik, V. E. ; Ivanov, S. A. ; Brown I. D., The chemical bond and atomic displacements in $\mathrm{SrTiO}_{3}$ from $X$-ray diffraction analysis, Acta Cryst., B51, 1995:942-951.

\section{Rueda-P,Jorge-E:}

Ph.D., Profesor Titular, Investigador Asociado, Grupo Óptica Moderna, Departamento de Física, Universidad de Pamplona, Colombia.

\section{Hernandes A.C.}

Ph.D., Profesor Titular, Investigador, Instituto de Física de São Carlos, Universidade de São Paulo, CP 369, CEP 13566-970, SP, Brazil. 